\title{
How best to log local temperatures?
}

\section{The climate community must work together to create a single, clean, comprehensive and open repository of detailed temperature data, say Peter A. Stott and Peter W. Thorne.}

\begin{abstract}
$\mathrm{n}$ the late twentieth century scientists were faced with a very basic question: is global climate changing? They stepped up to that challenge by establishing three independent data sets of monthly global average temperatures. Those data sets, despite using different source data and methods of analysis, all agree that the world has warmed by about $0.75^{\circ} \mathrm{C}$ since the start of the twentieth century (specifically, the three estimates are $0.80,0.74$ and $0.78^{\circ} \mathrm{C}$ from 1901-2009). Together with many other lines of evidence including rising sea levels and retreating ice $^{1}$, these data sets provide a compelling large-scale picture of the changing climate.
\end{abstract}

Now a new question needs to be answered: how exactly will the climate change from place to place? Transport infrastructure, hospital admissions, energy consumption and many other societal needs are affected by local temperature extremes, not by global average temperatures. Delegates to the World Meteorological Organization (WMO)'s Third World Climate Conference in September 2009 agreed on the need "to strengthen production, availability, delivery and application of science-based climate prediction and services" to help address these challenges. This is a high-level congress that has spurred great change in the past: their two previous meetings, in 1979 and 1990, led to the formation of the Intergovernmental Panel on Climate Change and the Global Climate Observing System (GCOS).

This new challenge requires climate data sets at daily or even shorter timescales, at a resolution of a few kilometres at most, to monitor how weather is changing and to feed local climate models. This would help to answer key questions such as whether the onset of the monsoon in the Western Ghats in India will be delayed, how the frequency of droughts in the Horn of Africa is changing, or whether Mexico City will experience more severe heatwaves in future. The only scientifically robust, global data sets we have for temperature are not suited to this purpose. The three monthly average data sets - made by the National Climate Data Center (NCDC, part of the US National Ocean and Atmospheric Administration, based in Boulder, Colorado); NASA's Goddard Institute for Space Studies in New York; and the UK Met Office Hadley Centre in Exeter, together with the University of East Anglia's Climatic Research Unit in Norwich, UK - only have resolutions of hundreds of kilometres.

Many efforts are under way to create climate data sets on smaller scales of time and space for particular regions, particularly in the United States and Europe. But these projects do not cover the entire globe, and they use a variety of different methodologies, making them difficult to integrate.

The climate community needs to gather temperature records from around the world - including measurements that are not currently freely available - into one, open database. Those data will then need to be corrected and adjusted in a transparent way, to ensure that the resulting data sets are sound, and to allay any public concerns that scientists could have skewed or 'spun' the data.

The UK Met Office proposed such a system to the WMO's Commission on Climatology in February ${ }^{2}$; the Commission endorsed it and recommended that the WMO take it up as a priority in collaboration with GCOS and the World Climate Research Program. The Met Office proposal (available at www.surfacetemperatures.org) is a massive scientific challenge that requires international collaboration. The climate-research community needs to convince nations with commercial interests

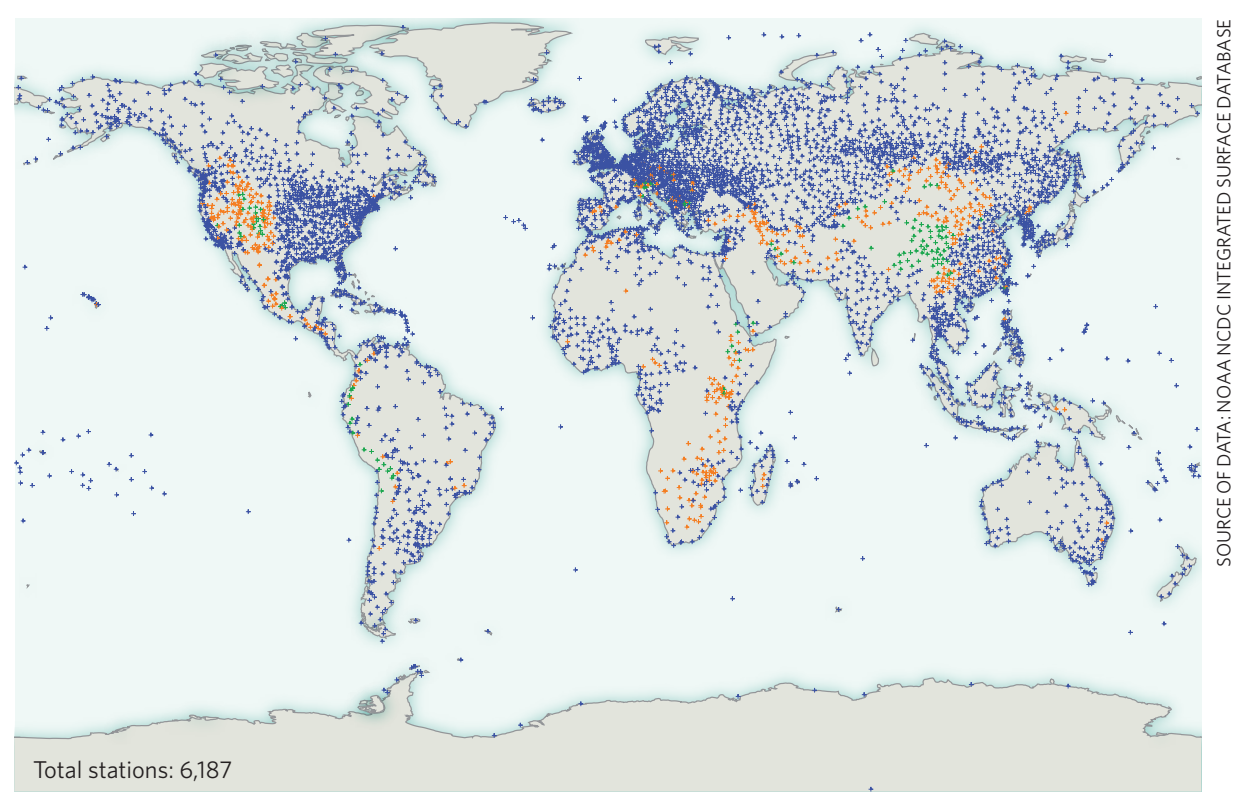

Figure 1 More than 6,000 stations have reported at three-hourly intervals for at least 15 years. Stations shown in blue are below 1,000 metres; orange are at 1,000 to 2,000 metres; green are higher than 2,000 metres. This is only about half of the data that should be in the global database.

\section{SUMMARY}

- Sub-daily, kilometre-scale temperature records are needed to monitor and predict local impacts of climate change.

- Climatologists need access to local weather information currently protected for commercial use.

- Records need to be corrected and cross-referenced transparently, to be sound and trustworthy.

in their weather records to free them up for scientific use and it must persuade governments to invest more heavily in collection, analysis and stewardship of climate data - topics that are not always seen as exciting.

\section{Boosting the databank}

The centre designated to hold the records is the World Data Center for Meteorology, hosted by the NCDC in Asheville, North Carolina. It already has a good archive, which includes records from more than 6,000 stations that have reported at three-hourly intervals for at least 15 years (Fig. 1). Near-global coverage is available at monthly resolution back to the late 
nineteenth century, at daily resolution back to the mid-twentieth century and at sub-daily resolution as far back as the 1970s. However, despite great effort on the centre's part, big chunks of data are missing. This can be for practical reasons - some data exist only on paper rather than electronically, or are otherwise not easily accessible - or for more complex financial or political reasons. In North America, the weather-data collectors are publicly funded and are not allowed to sell their data for commercial gain, making data sharing easy. Elsewhere, most national weather services are obliged to be cost-neutral or to turn a profit. Stationlevel data is one of their greatest assets, which they sell for speciality forecasting or other purposes. As a result, many rights-holders do not provide open access to all their data.

If all known data could be incorporated into the World Data Center archives, the database would more than double in size. This kind of 'data rescue' usually gets little political attention, is largely underfunded and is dependent on national goodwill. We hope that the WMObacked challenge will provide the momentum to improve these holdings.

One good model for this type of data rescue and dissemination is the marine International Comprehensive Ocean-Atmosphere Data Set (ICOADS) (http://icoads.noaa.gov). Since its inception in 1985, a large section of the marine-sciences community has pooled resources, contacts and expertise to create the most globally comprehensive set of marine meteorological and oceanographic measurements - from sea temperature to air pressure — going back to 1662 . ICOADS records are available without restriction and are updated in near real-time. Setting up a databank like this is a necessary first step for climate researchers. But it is not the end of the story. Corrections must also be applied to make the data useful to climatologists.

In many cases a weather station's instrumentation, location, time of observation, or environment (such as proximity to buildings) has changed. While such changes aren't of concern for weather forecasting, which deals with dayto-day temperature swings of several degrees, they are relevant for monitoring long-term decadal changes, where fractions of a degree make a difference. Unfortunately, the timing and effect of most of these changes have not been recorded. Over the past 60 years, the WMO has worked to standardize measurement practices by national meteorological services, but there are still plenty of data collected not using these standards. In addition, the person reading the thermometer, an analyst

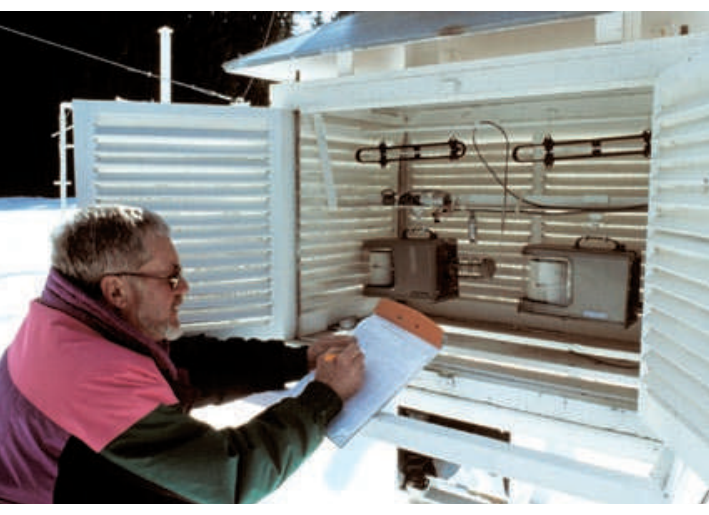

but also have known, realistic errors from physical factors such as instrument changes added into them. Analysts would apply their algorithms to these control data sets, and their results would be checked. Such tests are not perfect; they rely on the accuracy of the climate models used to construct the control data, for example. But our experience of doing this with weather-balloon data ${ }^{2}$ has shown the value of the procedure.

The final product would be a broad range of independently derived data sets, along with a consistent assessment of their strengths and weaknesses. It might then be possible to produce an overall best data or automated software may have carried out quality checks, and discarded or altered some data without recording this.

The three institutions overseeing global monthly temperature monitoring have each made different decisions about which weather stations to include, how to perform qualitycontrol checks, how to correct for data jumps (due to site moves, missing data and so on) and how to deal with rising temperatures caused by urbanization ${ }^{1}$. That these data sets agree on the scale of global temperature changes, and on many aspects of temperature variability at hemispheric and continental scales, attests to the reliability of these correction schemes. But they are not necessarily suitable for data at higher time resolution and at smaller scales. Different approaches are needed to correct for errors in data taken on a sunny summer day versus a dank winter day, for example. And while it is desirable to correct for the impact of urban development on local temperatures when assessing global climate change, it might be better to maintain those temperature increases in local-scale databases - they do, after all, represent a real local effect.

\section{Cleaning the records}

The Met Office's proposed solution is to invite anyone, from individuals to professional bodies, to create their own rules and algorithms for correcting the databank, using independently gathered funds. Analyses would be sanctioned by the WMO-backed project if a paper had been published in a peer-reviewed journal and the analysts could provide a full audit trail of their processing. By creating such a suite of independent data sets, it will become possible to assess the sensitivity of the data to different sorts of corrections.

Climatologists will need a way of separating the wheat from the chaff. One way to do this is to provide the analysts with a number of constructed 'control' data sets. These would follow the normal variability of weather and climate tainty on the data.

Such a significant effort will come at considerable cost, involving perhaps a full-time staff of several dozen people, a start-up time of several years, and in the order of millions of dollars in funds. Arguably, the single biggest challenge is to obtain access to the data currently guarded by rights-holders for its commercial value. The WMO already has a resolution in place for 'essential' weather and climate data to be exchanged free of charge. But the resolution was conceived to help weather forecasters and so is generally only applied to real-time data, and organizations can, and do, list exemptions for which they wish to charge. The full spirit of this resolution should be applied firmly to all sub-daily temperature records.

The concept we have outlined above has so far been developed by a few individuals at a single institution. Developing a new temperature database requires international acceptance and input. To this end, the Met Office is hosting a workshop this September (see www.surfacetemperatures.org), which will include statisticians, metrologists and economists as well as meteorologists. Ideally, the participants will agree on a framework for the creation of a new databank, and the construction and testing of new data sets. Then, with a WMO guiding committee, the hard work of getting funding and building the databank can begin.

Peter Stott is head of the Climate Monitoring and Attribution group at the Met Office Hadley Centre, Exeter EX13PB, UK. Peter Thorne, has recently left the Met Office to join the Cooperative Institute for Climate and Satellites, Asheville, North Carolina 28801-5001, USA. Both authors are on the organizing committee for the September workshop.

e-mail:peter.stott@metoffice.gov.uk Meteorol. Soc. 91, in the press (2010).

2. Titchner, H. A. et al. J. Clim. 22, 465-485 (2009). set, or at least an estimate of the range of uncer-

1. Kennedy, J. J. et al. In State of the Climate 2009, Bull. Am 